\title{
In situ fabrication of radiopaque microcapsules for oral delivery and real-time gastrointestinal tracking of Bifidobacterium
}

This article was published in the following Dove Press journal: International Journal of Nanomedicine

\author{
Zhengzou Fang ${ }^{1, *}$ \\ Rong Jiang ${ }^{2, *}$ \\ Lirong Zhang ${ }^{3, *}$ \\ Yunchao $\mathrm{Wu}^{2}$ \\ Xuefen Zhao ${ }^{2}$ \\ Lulu Zhao ${ }^{2}$ \\ Jiangang $\mathrm{Li}^{4}$ \\ Shengqiang Zou' \\ Miaomiao Zhang ${ }^{2}$ \\ Fengyi Du ${ }^{1,2}$ \\ 'Department of Hepatosis, The Third \\ Hospital of Zhenjiang Affiliated Jiangsu \\ University, ${ }^{2} \mathrm{School}$ of Medicine, \\ Jiangsu University, ${ }^{3}$ Department \\ of Radiology, Affiliated Hospital of \\ Jiangsu University, ${ }^{4}$ Tianyi Health \\ Sciences Institute (Zhenjiang) Co., \\ Ltd. Zhenjiang, People's Republic \\ of China \\ *These authors contributed equally \\ to this work
}

Correspondence: Miaomiao Zhang;

Fengyi Du

Email 278989547@qq.com;

biodfy@qq.com
Introduction: Although oral administration of Bifidobacterium is a promising approach for diseases, lack of resistance to harsh conditions and real-time tracking in gastrointestinal system in vivo are still major challenges in basic research and clinical applications.

Materials and methods: In this study, we fabricated a chitosan-coated alginate microcapsule loaded with in situ synthesized barium sulfate $\left(\mathrm{CA} / \mathrm{BaSO}_{4}\right.$ microcapsule) for oral Bifidobacterium delivery and real-time X-ray computed tomography (CT) imaging. $\mathrm{CA} / \mathrm{BaSO}_{4}$ microcapsules containing the Bifidobacterium were prepared in situ by one-step electrostatic spraying method, and then coated with chitosan.

Results: The results indicated that $\mathrm{CA} / \mathrm{BaSO}_{4}$ microcapsules with an average diameter of approximately $200 \mu \mathrm{m}$ possessed favorable mechanical stability and X-ray attenuation capacity. Encapsulation of Bifidobacteria in the $\mathrm{CA} / \mathrm{BaSO}_{4}$ microcapsules exhibited superior resistance to cryopreservation and gastric acid environment in vitro. After oral administration in mice, these $\mathrm{CA} / \mathrm{BaSO}_{4}$ microcapsules could be real-time visualized by CT imaging and readily reached the intestine to release Bifidobacteria.

Conclusion: The radiopaque $\mathrm{CA} / \mathrm{BaSO}_{4}$ microcapsules provide a novel platform for efficient protection, non-invasive real-time monitoring and intestinal-targeted Bifidobacterium delivery.

Keywords: alginate, microcapsule, CT imaging, intestinal-targeted, Bifidobacterium

\section{Introduction}

Bifidobacterium are defined as a group of living microorganism supplements that confer health benefits on the host when administered in adequate amounts. ${ }^{1}$ When body lacks a certain amount of Bifidobacterium, it will result in a series of diseases, such as promote harmful bacteria reproduction, ${ }^{2}$ change intestinal flora caused diarrhea, ${ }^{3}$ increase tumor growth, ${ }^{4}$ reduce body immunity and so on. ${ }^{5}$ Lactobacillus case often used as effectors of host functions could play an important role in maintaining human health by controlling other intestinal microorganisms capable of producing harmful effects. Lactobacillus case played an important role in prevention of enteric infections, a low dose of which was enough for protection against intestinal infections by secreting IgA into the intestinal lumen, thus providing adequate defenses for mucosal surface. Studies have suggested that secretory immune system of gut might be stimulated most effectively by microbes, which could actively colonize the mucosal surface of the intestinal tract and release adequate protective antigens. ${ }^{6}$ Thus, delivery of Bifidobacterium to influence and modulate microbiome compositions can potentially impact the treatment of human diseases. ${ }^{7}$ When oral Bifidobacterium pass through mouth, pharynx, esophagus, stomach and finally reach intestine, they start to exert the 
functional effect on intestinal inflammation. However, certain exogenous Bifidobacterium are extremely sensitive to low pH gastric acid. ${ }^{8,9}$ A large amount of Bifidobacterium might have died before they reached the intestine if they came into direct contact with gastric acid in stomach. ${ }^{10-14}$ Thus, how to protect Bifidobacterium in acidic environments is still a significant challenge.

Up to now, encapsulation is the main way to protect Bifidobacterium. ${ }^{15-18}$ Alginate-based microcapsules (AMs) are widely used for encapsulation of Bifidobacterium. Many researchers report that encapsulation of Bifidobacterium in AMs can help Bifidobacterium to resist gastric acid and guarantee adequate living Bifidobacterium to reach intestine. ${ }^{19-25}$ However, the application of AMs are limited due to their unstable property. So, researchers have explored a number of methods to improve the stability of AMs. Chitosan as a mucoadhesive polymer is a biocompatible and biodegradable cationic polysaccharide, which is synthesized by partial deacetylation of chitin. ${ }^{26}$ The role of primary amino groups, electrostatic attraction, hydrogen bonding and hydrophobic have an effect on aggregation of mucin in the presence of chitosan. Reducing the number of amino groups through their half acetylation not only results in expansion of chitosan's $\mathrm{pH}$ solubility window up to $\mathrm{pH} 7.4$ but also reduces its capacity to aggregate mucin. ${ }^{27,28}$ Gombotz and $\mathrm{Wee}^{29}$ reported that coating polycationic compound chitosan on the surface of AMs enhanced the stability of physical and chemical property. Malmo et $\mathrm{al}^{30}$ also reported that the survival of Bifidobacterium entrapped in AMs could be increased through chitosan coating. However, such method results in another problem; although the protection effect in the stomach and intestinal-targeted Bifidobacterium delivery is improved to a certain extent, encapsulation of Bifidobacterium in AMs coated with chitosan cannot be monitored in the whole digestive system.

In this study, we attempt to fabricate a novel intestinaltargeted and real-time monitoring CA microcapsule for $\mathrm{pH}$-responsive protection of Bifidobacterium in stomach and rapid release of Bifidobacterium in small intestine. In the formation process of chitosan-coated alginate microcapsule loaded with in situ synthesized barium sulfate $\left(\mathrm{CA} / \mathrm{BaSO}_{4}\right)$ microcapsules, barium ions not only solidified the alginate droplets, which could be further consolidated by coating with chitosan and removed off via following citric acid liquidation, but also reacted with sulfate ions to synthesize $\mathrm{BaSO}_{4}$ precipitates in situ acting as radiopaque imaging agent within the resultant microcapsules. After surface coating on the surface of alginate microcapsule, the chitosan improved protection for
Bifidobacterium to guarantee the survival of Bifidobacterium in stomach and readily intestinal mucoadhesive characteristics to guarantee the release of Bifidobacterium in the intestine. When the prepared $\mathrm{CA} / \mathrm{BaSO}_{4}$ microcapsules containing Bifidobacterium enter the extremely low $\mathrm{PH}$ stomach environment, and take advantage of the electrostatic repulsion of the positively charged chitosan, it is hard for the gastric acid in stomach to diffuse across the barium-mediated alginate (BA) microcapsules and then the Bifidobacterium in BA microcapsules are efficiently protected. However, the Bifidobacterium release quickly from the BA microcapsules to the intestine due to neutral $\mathrm{pH}$ environment and mechanical agitation, and this process could be visualized in real time using computed tomography (CT) imaging by radiopaque $\mathrm{BaSO}_{4}$ nanocluster within microcapsules.

\section{Materials and methods \\ Materials}

Sodium alginate (molecular weight: 216.123, viscosity: $200 \pm 20$ mpa.s.) was purchased from Sigma-Aldrich Co. (St Louis, MO, USA). $\mathrm{Na}_{2} \mathrm{SO}_{4}$ (anhydrate, purity $\geq 99.0 \%$ ), $\mathrm{BaCl}_{2}$ (dihydrate, purity $\geq 99.0 \%$ ), chitosan (molecular weight: 1,526.454, viscosity: 100-200 mpa.s., deacetylation $\geq 95 \%$ ) and liquid paraffin were purchased from Sinopharm Chemical Reagent Co. Ltd. All other chemicals, including pepsin, trypsin, sodium citrate, sodium chloride, hydrochloric acid $(\mathrm{HCl})$, sodium hydroxide $(\mathrm{NaOH})$, were of analytical grade. Sterile water and sterile operation were used throughout the experiments.

\section{Microorganism and solution}

Bifidobacterium (strain name: TR17, number: CCTCCM 2017265) from National Center for Preservation of China were used throughout the experiments. MRS medium was used to activate Bifidobacterium. Simulate gastric acid ( $\mathrm{pH} 2.5)$ was prepared by adjusting the $\mathrm{pH}$ of the prior solution to 2.5 with $0.1 \mathrm{~mol} / \mathrm{L} \mathrm{HCl}$ solution. Simulated intestinal fluid was prepared by dissolving $6.8 \mathrm{~g}$ of $\mathrm{KH}_{2} \mathrm{PO}_{4}$ into $500 \mathrm{~mL}$ of sterile water and adjusting $\mathrm{pH}$ to 7.0 with $0.1 \mathrm{~mol} / \mathrm{L} \mathrm{NaOH}$ solution, dissolving $10 \mathrm{~g}$ of trypsin in a small amount of water, and then mixing the two solutions and metering the volume to $1,000 \mathrm{~mL}$.

\section{Preparation of $\mathrm{CA} / \mathrm{BaSO}_{4}$ microcapsules loading Bifidobacterium}

$\mathrm{CA} / \mathrm{BaSO}_{4}$ microcapsules loading Bifidobacterium were fabricated using three steps as shown in Scheme 1. In the first step, the alginate beads loading Bifidobacterium were simultaneously prepared by an electrostatic spraying method. 


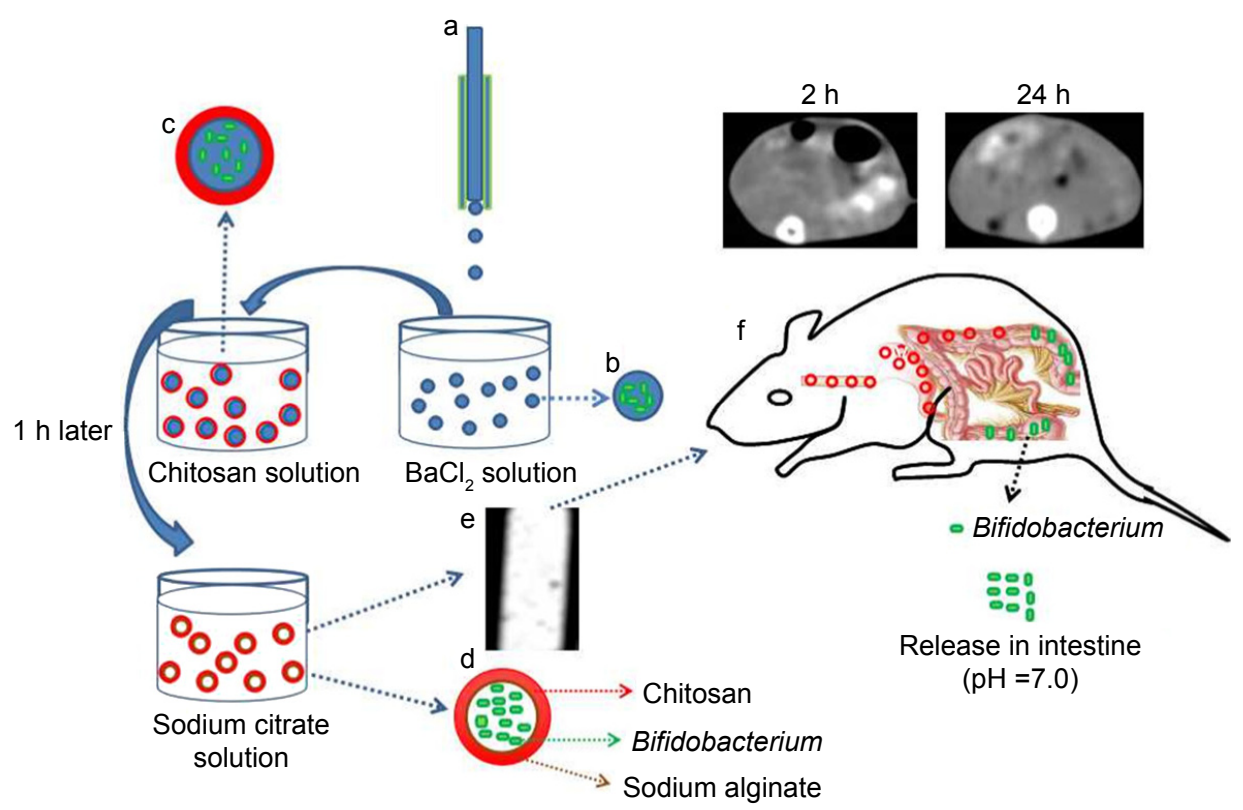

Scheme I Illustration of the preparation process of the $\mathrm{CA} / \mathrm{BaSO}_{4}$ microcapsules for $\mathrm{pH}$-responsive protection and release of Bifidobacterium. (a) A droplet microfluidic device, (b) formation of BA beads, (c) chitosan-coated BA beads, (d) sodium citrate liquidation, (e) CT image of $\mathrm{CA} / \mathrm{BaSO}_{4}$ microcapsules, (f) real-time imaging of CA/BaSO microcapsules and releasing Bifidobacterium in vivo.

Abbreviations: $\mathrm{CA} / \mathrm{BaSO}_{4}$, chitosan-coated alginate microcapsule loaded with in situ synthesized barium sulfate; $\mathrm{CT}$, computed tomography.

Briefly, Bifidobacterium was mixed with $1 \%$ sodium alginate and $0.5 \% \mathrm{Na}_{2} \mathrm{SO}_{4}$ solution as droplet fluids. Then, the mixed solution was subsequently sprayed into a bath containing $\mathrm{BaCl}_{2}(0.6 \mathrm{~mol} / \mathrm{L})$ under electrostatic field 20 voltage, and rapidly cress-linked by barium ions to form alginate beads. Meanwhile, $\mathrm{BaSO}_{4}$ nanoclusters were in situ synthesized by the reaction between $\mathrm{SO}_{4}{ }^{2-}$ premixed in the alginate solution and excessive $\mathrm{Ba}^{2+}$ in the collection bath. In the second step, chitosan was coated onto the alginate beads by electrostatic attraction. To achieve satisfactory $\mathrm{pH}$-responsive performance and stable core-shell structure, resultant alginate beads loaded with Bifidobacterium were immersed in 1\% chitosan solution with $1 \mathrm{~h}$ of continuous stirring. ${ }^{31}$ In the last step, CA/ $\mathrm{BaSO}_{4}$ microcapsules were obtained by immersing alginate beads coated with chitosan into the $1 \%$ sodium citrate solution for $5 \mathrm{~min}$ with continuous stirring. The prepared CA/ $\mathrm{BaSO}_{4}$ microcapsules containing Bifidobacterium were washed with pure water three times and preserved in normal saline at $4^{\circ} \mathrm{C}$.

To meet the visibility criteria, the minimum content of $\mathrm{BaSO}_{4}$ in microspheres should be approximately $5 \mathrm{wt} \%$ for $\mathrm{CT}$ and $10 \mathrm{wt} \%$ for fluoroscopy. ${ }^{32}$ Unlike physically mixing $\mathrm{BaSO}_{4}$ in microcapsules, we introduced $\mathrm{NaSO}_{4}$ in the dispersed phase and assumed that all $\mathrm{SO}_{4}{ }^{2-}$ ions could react with $\mathrm{Ba}^{2+}$ ions completely in the collection bath to form $\mathrm{BaSO}_{4}$. Thus, the weight of $\mathrm{BaSO}_{4}$ in the $\mathrm{CA} / \mathrm{BaSO}_{4}$ microcapsules can be estimated by the initial $\mathrm{NaSO}_{4}$ concentrations.
The range of $\mathrm{NaSO}_{4}$ in the dispersed phase and higher initial $\mathrm{NaSO}_{4}$ concentrations in the dispersed phase yielded higher $\mathrm{BaSO}_{4}$ contents in $\mathrm{CA} / \mathrm{BaSO}_{4}$ microcapsules. So, when the concentration of $\mathrm{NaSO}_{4}$ in the dispersed phase was $0,0.025$, 0.05 and $0.1 \mathrm{~mol} / \mathrm{L}$, the corresponding content of $\mathrm{BaSO}_{4}$ was estimated to be $0,0.25 \mathrm{wt} \%, 0.5 \mathrm{wt} \%$ and $1 \mathrm{wt} \%$ in the hydrated $\mathrm{CA} / \mathrm{BaSO}_{4}$ microcapsules, respectively.

\section{Morphological analyses}

We used the following three methods to analyze $\mathrm{CA} / \mathrm{BaSO}_{4}$ microcapsules.

First, a digital camera was used to observe the morphology of the alginate beads and $\mathrm{CA} / \mathrm{BaSO}_{4}$ microcapsules in pure water. The size of beads and microcapsules in pure water were determined by imageJ software.

Second, a fluorescence microscope was used to study the distribution of Bifidobacterium in the microcapsules. Bifidobacterium was incubated with apoptosis assays kit C1056 solution at room temperature for $30 \mathrm{~min}$ before made microcapsules. A confocal laser scanning fluorescence microscope (Zeiss LSM-710) was used to observe and record the fluorescence emission from Bifidobacterium inside the microcapsules, which were excited at $346 \mathrm{~nm}$ wavelength. Bifidobacterium presented blue fluorescence. ${ }^{2}$

Third, for scanning electron microscopy (SEM), the CA/ $\mathrm{BaSO}_{4}$ microcapsules were sprinkled on the double-sided adhesive and then sprayed with gold powder $(100 \mu)$. 
Accelerating voltage was $10 \mathrm{kV}$ and the observation time required was as short as possible.

\section{Characterizations of $\mathrm{BaSO}_{4}$ in microcapsules}

An aqueous dispersion of Bifidobacterium-encapsulated $\mathrm{CA} / \mathrm{BaSO}_{4}$ microcapsules was deposited onto clean water and then dried under frozen vacuum drying for $24 \mathrm{~h}$. The crystal structure of $\mathrm{BaSO}_{4}$ synthesized in situ in BA microcapsules was measured by a powder X-ray diffraction (XRD) instrument with $2 \theta$ ranging from $5.0^{\circ}$ to $90.0^{\circ}$ in a step of $0.02^{\circ}$ under $\mathrm{Cu}$ Ka radiation. ${ }^{33}$

\section{Endurance experiments in simulated gastric acid}

To investigate the protection of microcapsules, same amount of naked Bifidobacterium, alginate bead-loaded Bifidobacterium and $\mathrm{CA} / \mathrm{BaSO}_{4}$ microcapsule-encapsulated Bifidobacterium were individually immersed into $15 \mathrm{~mL}$ of $\mathrm{pH} 2.5$ simulated gastric acid solutions at $37^{\circ} \mathrm{C}$ for $2 \mathrm{~h}$ with continuous oscillation at $120 \mathrm{rpm}$. At regular intervals, the same amount of free Bifidobacterium solution, alginate bead-loaded Bifidobacterium and $\mathrm{CA} / \mathrm{BaSO}_{4}$ microcapsuleencapsulated Bifidobacterium were shifted into $15 \mathrm{~mL}$ of $0.06 \mathrm{~mol} / \mathrm{L}$ sodium citrate solution until the beads and microcapsules were dissolved under vigorous oscillation. Then, these Bifidobacterium were incubated, respectively, on the culture plate for $24 \mathrm{~h}$. At last, the viable count of Bifidobacterium was tested by plate count method and the survival was the ratio of viable count and whole count. ${ }^{2}$

\section{Dissolution experiments in simulated gastric acid and intestine fluid}

To investigate the release characteristics, same amount of Bifidobacterium loaded by alginate beads and Bifidobacterium loaded by $\mathrm{CA} / \mathrm{BaSO}_{4}$ microcapsules were individually immersed into $50 \mathrm{~mL}$ of $\mathrm{pH} 2.5$ simulated gastric acid solution at $37^{\circ} \mathrm{C}$ for $2 \mathrm{~h}$ with continuous oscillation at $120 \mathrm{rpm}$. At regular intervals, the concentration of Bifidobacterium in the surrounding medium was analyzed by UV-vis at a wavelength $600 \mathrm{~nm}$. Then, the samples were quickly shifted from pH 2.5 simulated gastric acid to $\mathrm{pH} 6.0$ simulated jejunum fluid with continuous oscillation. Then, $3 \mathrm{~h}$ later, the samples were quickly shifted into $\mathrm{pH} 7.0$ simulated ileum fluid. After $4 \mathrm{~h}$ of continuous oscillation, the samples were immersed into $\mathrm{pH} 8.0$ simulated cecum for $1 \mathrm{~h}$. All steps of the experiment were carried out at $37^{\circ} \mathrm{C}$ in a shaker at $120 \mathrm{rpm}$ to reproduce the dynamic movements of the intestine, and the concentration change of Bifidobacterium with time was measured using the UV-vis at wavelength $600 \mathrm{~nm}$ until Bifidobacterium were released completed. ${ }^{2}$

\section{Animal experiments}

All animal experiments in this study were executed according to the protocol approved by the Animal Management Rules of the Ministry of Health of the People's Republic of China and approved by the Institutional Animal Care and Use Committee of Jiangsu University. Six- to 8-week-old female C57BL/6 mice were purchased from Model Animal Genetics Research Center of Jiangsu University (Zhenjiang, People's Republic of China). All efforts were made to minimize animals' suffering and to reduce the number of animals used.

\section{Induction of colitis and treatment}

Colitis animal models were induced in C57BL/6 mice with $2.0 \%$ dextran sulfate sodium (DSS) (molecular weight $36-50 \mathrm{kDa}$ ) dissolved in drinking water (days 1-11). Normal mice were given water. Vehicle control (water), Bifidobacterium $\left(2.4 \times 10^{9} \mathrm{CFU}\right)$, microcapsules $(0.52 \mathrm{~g} / 20 \mathrm{~g})$, sulfasalazine $0.03 \mathrm{~g} /(\mathrm{kg} / \mathrm{d})$ and $\mathrm{CA} / \mathrm{BaSO}_{4}$ microcapsules containing Bifidobacterium $\left(0.6,1.2,2.4 \times 10^{9} \mathrm{CFU}\right)$ were given orally from day 3 to day $11 .{ }^{34}$

\section{Clinical scoring and histological analysis}

Body weight, stool consistency and the presence of gross blood in feces and at the anus were observed every day. The disease activity index (DAI) was calculated by assigning well-established and validated scores. Briefly, the following parameters were used for calculation: 1$)$ diarrhea $(0$ points $=$ normal, 2 points $=$ loose stools, 4 points $=$ watery diarrhea $) ; 2$ ) hematochezia $(0$ points $=$ no bleeding, 2 points $=$ slight bleeding, 4 points = gross bleeding). At day 11 following induction of colitis, animals were sacrificed, the colon was removed and pieces of colonic tissue were used for vivo analysis. For histological analysis, part of the colon was fixed in $4 \%$ paraformaldehyde and embedded in paraffin. Sections were stained with $\mathrm{H} \& \mathrm{E}$ and colonic sections was graded as follows: 0) no signs of inflammation; 1) low leukocyte infiltration; 2) moderate leukocyte infiltration; 3) high leukocyte infiltration, moderate fibrosis, high vascular density, thickening of the colon wall, moderate goblet cell loss and focal loss of crypts; and 4) transmural infiltrations, massive loss of goblet cell, extensive fibrosis and diffuse loss of crypts. ${ }^{34-36}$

\section{In vivo real-time imaging of $\mathrm{CA} / \mathrm{BaSO}_{4}$ microcapsules}

The $\mathrm{X}$-ray visibility of resultant $\mathrm{CA} / \mathrm{BaSO}_{4}$ microcapsules was assessed by using a 16-slice spiral CT instrument (SOMATOM 
Sensation; Siemens, Berlin, Germany) under a scanning voltage of $80 \mathrm{kV}$ and a current of $120 \mathrm{~mA}$. Mice were kept under standard feeding condition and no feeding was treated for $24 \mathrm{~h}$ prior to the following procedure. Briefly, mice were administrated by gavage $0.52 \mathrm{~g} \mathrm{CA} / \mathrm{BaSO}_{4}$ microcapsules according to a method described elsewhere. The located efficacy of intestinal of mice and the visibility of $\mathrm{CA} / \mathrm{BaSO}_{4}$ microcapsules were further assessed by $\mathrm{CT}$ at designated time intervals.

\section{I6S rRNA gene sequence analysis}

Sequences generated from pyrosequencing barcoded 16S rRNA gene PCR amplicons were quality filtered. The sample of genomic DNA was extracted by using the US MoBio PowerSoil HTP 96 Well Soil DNA Isolation Kit. The purity and concentration of DNA was tested by the Onedrop instrument and agarose gel electrophoresis. A total of $2.5 \mathrm{ng}$ diluted genomic DNA was used as a template. American Promega GoTaQ Hot Start Colorless Master Mix and high fidelity enzyme with specific primers Barcode were employed to ensure the amplification efficiency and accuracy of PCR. Pico Green fluorescence quantitative analysis was performed to detect the concentration of DNA of PCR products. The product was purified by the QIAquick PCR Purification Kit. The amplification of targeting genes was performed by the $16 \mathrm{~S} V 4$ region primer 515F (5'-GTGCCGCCGCCGCGGTAA-3'), 806R (5'-GGACTACHVGGGTWTCTAAT-3'), which were tested by the fluorescence quantitative and Agilent 2200 TapeStation electrophoretic platform. MiSeq was further tested when the results were satisfied. Sequences were removed if they were shorter than 200 nucleotides and contained primer mismatches, ambiguous bases, uncorrectable barcodes or homopolymer runs in excess of six bases. The remaining sequences were collected and analyzed using the open source software package Quantitative Insights Into Microbial Ecology. 16S rRNA gene sequences were assigned to operational taxonomic units (OTUs) using UCLUST with a threshold of 97\% pair-wise identity and then classified taxonomically using the Ribosomal Database Project classifier 2.0.1. . $^{37,38}$

\section{Statistical analysis}

All data were presented by mean \pm standard deviation. Statistical comparisons were statistically analyzed by oneway ANOVA. The values of $P<0.05$ were considered statistically significant.

\section{Results and discussion Morphological analyses}

$\mathrm{CA} / \mathrm{BaSO}_{4}$ microcapsules have been successfully synthesized in situ using barium-mediated gelation, chitosan coating and sodium liquidation route. At first, we chose electrostatic spraying and metal ion cross-linking to form the BA beads, as shown in Figure 1A. During this process, barium ions served dual-function roles in formation of alginate gelation and $\mathrm{BaSO}_{4}$ nanoclusters. Then, the polycationic chitosan molecules were coated on the surface of these BA beads via polyanionic alginate molecules due to electrostatic interaction. Finally, alginate gel in the BA beads interiors was liquified by sodium citrate-mediated competitive chelation, but transparent shell was still kept in good condition due to chitosanalginate complexes' interaction. ${ }^{1,39}$ Consequently, $\mathrm{CA} / \mathrm{BaSO}_{4}$ microcapsules with hollow structure were obtained by virtue of liquidation of internal alginate gel and surface electrostatic interaction, as shown in Figure $1 \mathrm{~B}$ and $\mathrm{C}$. It was worth noting that the average diameters of $\mathrm{BA}$ beads and $\mathrm{CA} / \mathrm{BaSO}_{4}$ microcapsules were $150 \mu \mathrm{m}$ and $200 \mu \mathrm{m}$, respectively. The as-prepared $\mathrm{CA} / \mathrm{BaSO}_{4}$ microcapsules became slight bigger than the original BA beads, which might be caused by slight swelling in the liquidation process.

To characterize the spatial structure of microcapsules and assess the viability of loaded Bifidobacterium, fluorescent staining was carried out, as shown in Figure 1D, in which viable Bifidobacterium exhibited blue fluorescence. A large number of bright blue fluorescence was obviously observed in the interior of microcapsule, indicating the presence of lots of Bifidobacterium with favorable viability. It was worth noting that almost no blue fluorescence appeared on the edge of the microcapsule. The differential distribution of Bifidobacterium in the microcapsule further confirmed welldefined core-shell structure. This closed hollow structure provided a superior environment for probiotic growing against external harsh conditions. SEM was performed to study the morphology of $\mathrm{CA} / \mathrm{BaSO}_{4}$ microcapsules. In Figure 1E, it was revealed that $\mathrm{CA} / \mathrm{BaSO}_{4}$ microcapsules possessed irregular loose spherical shape, which ascribed to the freezedrying process. In Figure 1F, SEM image showed crosssectional views of typical Bifidobacterium-loaded $\mathrm{CA} / \mathrm{BaSO}_{4}$ microcapsules, demonstrating the existence of huge hollow structure in the microcapsule interior. In addition, chitosan post-coating prevented Bifidobacterium distributing on the external surface and leaking from microcapsule. In view of space advantage, this core-shell structure will be conducive to avoid interior Bifidobacterium (Bifidobacterium marked by red circle) contacting with external hash surrounding and reduce the death rate, resulting in the formation of a favorable closed environment.

The crystal structure of $\mathrm{BaSO}_{4}$ nanoclusters synthesized in situ was identified by XRD, as shown in Figure 2A. The main diffraction peaks and relative intensities in the XRD patterns 

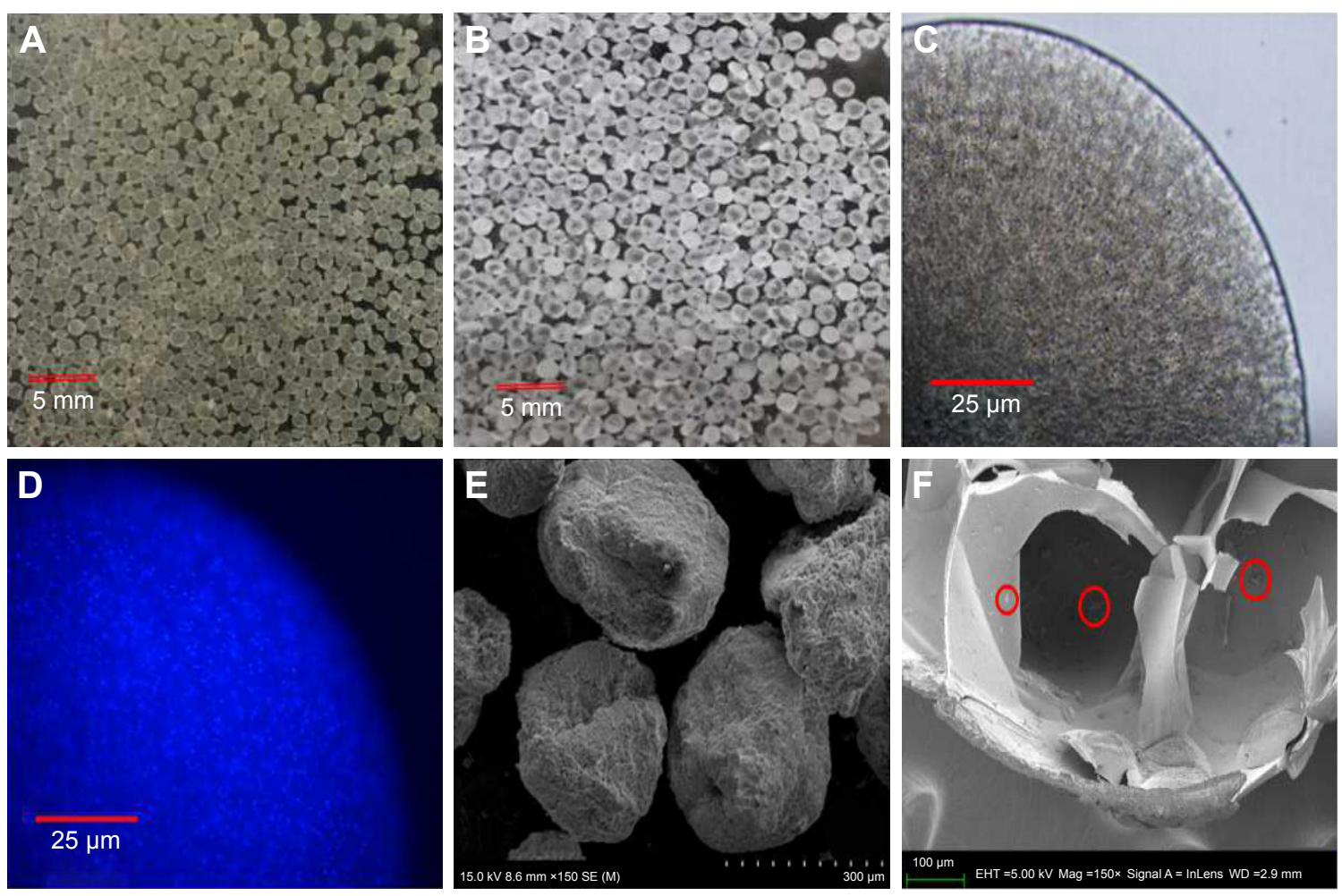

Figure I Morphology characterization of $\mathrm{CA} / \mathrm{BaSO}_{4}$ microcapsules. Optical images of $(\mathbf{A}) \mathrm{BA}$ beads and $(\mathbf{B}) \mathrm{CA} / \mathrm{BaSO}_{4}$ microcapsules in pure water at room temperature. Micrographs of $\mathrm{CA} / \mathrm{BaSO}_{4}$-loading Bifidobacterium under (C) bright field and (D) fluorescence field. Bifidobacterium were stained by Hoechst (D). SEM images of surface (E) and inside (F) $\mathrm{CA} / \mathrm{BaSO}_{4}$ microcapsules. Bifidobacterium are marked by red circle.

Abbreviations: $\mathrm{CA} / \mathrm{BaSO}_{4}$, chitosan-coated alginate microcapsule loaded with in situ synthesized barium sulfate; $\mathrm{BA}$, barium-mediated alginate; SEM, scanning electron microscopy.

displayed a main broad diffraction peak at $43.02^{\circ}$, which matched well with the reference of orthorhombic $\mathrm{BaSO}_{4}$ crystal structure. This result implied that $\mathrm{BaSO}_{4}$ crystallites were formed in situ between sodium alginate and barium chloride during the formation of alginate gelation process. The x-ray attenuation capability of $\mathrm{CA} / \mathrm{BaSO}_{4}$ microcapsules was characterized by CT scanning. As shown in Figure 2B, CT signal intensity gradually increased with an increase of
$\mathrm{NaSO}_{4}$ concentration from $0 \mathrm{mg} / \mathrm{mL}$ to $7.5 \mathrm{mg} / \mathrm{mL}$. We found that $\mathrm{CA} / \mathrm{BaSO}_{4}$ microcapsules gave much higher signal intensity and produced similar contrast with iodixanol solution. The results revealed that $5 \mathrm{mg} / \mathrm{mL}$ concentration of $\mathrm{NaSO}_{4}$ can provide an equivalent contrast ability relative to clinical iodixanol. The minimum dose in administration is highly favorable as it significantly reduces side effects. In Figure 2C, we can observe lots of barium sulfate nanoclusters of which
A

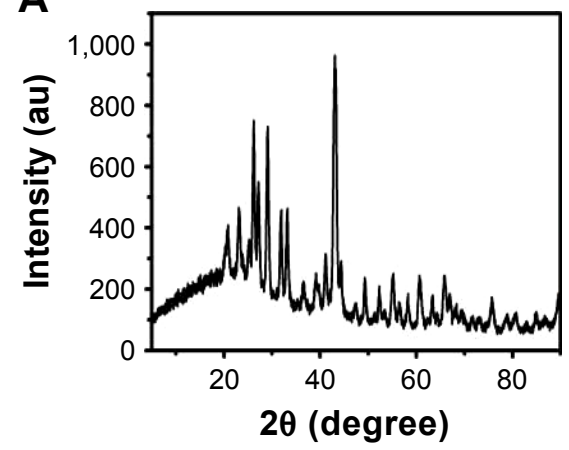

B

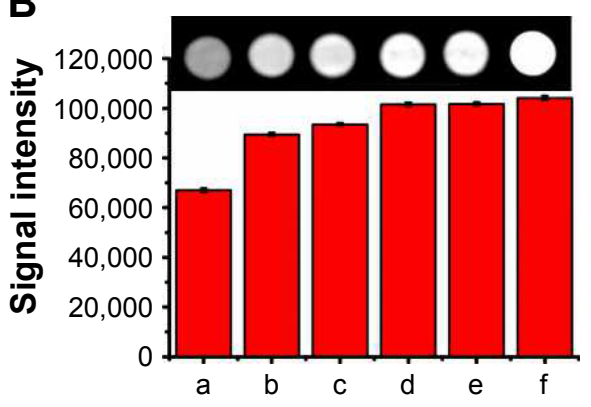

C

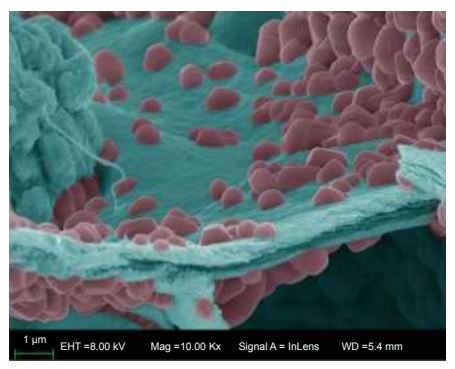

Figure 2 (A) $\mathrm{XRD}$ patterns of $\mathrm{CA} / \mathrm{BaSO}_{4}$ microcapsules measured with $2 \theta$ ranging from $5^{\circ}$ to $90.0^{\circ}$ in a step of $0.02^{\circ}$ under a $\mathrm{Cu} \mathrm{Ka}$ radiation. (B) $\mathrm{CT}$ images of $\mathrm{CA} / \mathrm{BaSO} \mathrm{H}_{4}$ microcapsules using various concentrations of $\mathrm{Na}_{2} \mathrm{SO}_{4}$ as injection liquid arranged from $0 \mathrm{mg} / \mathrm{mL}$ to $7.5 \mathrm{mg} / \mathrm{mL}$ (b-e: $0,2.5,5,7.5 \mathrm{mg} / \mathrm{mL}$ ); phospate buffered saline was used as the negative control (a) and iodixanol solution was used as the positive control (f). (C) SEM images of barium sulfate nanoclusters.

Abbreviations: $\mathrm{XRD}$, x-ray diffraction; $\mathrm{CA} / \mathrm{BaSO}_{4}$, chitosan-coated alginate microcapsule loaded with in situ synthesized barium sulfate; $\mathrm{CT}$, computed tomography; SEM, scanning electron microscopy. 
the average size was $679.06 \mathrm{~nm}$ using statistical analysis in the SEM image by imageJ.

\section{The protective effect of $\mathrm{CA} / \mathrm{BaSO}_{4}$ microcapsules on Bifidobacterium in vitro}

The protective effect of $\mathrm{CA} / \mathrm{BaSO}_{4}$ microcapsules on viability of the Bifidobacterium was evaluated under simulated gastric acid conditions. Along with the change of ingredients, food intake and human body, the $\mathrm{pH}$ value of the gastric acid in human body is usually about $1.8-5.0 .{ }^{34}$ Therefore, the $\mathrm{pH} 2.5$ simulated gastric acid was chosen as the model gastric acid to investigate the protection effect of $\mathrm{CA} / \mathrm{BaSO}_{4}$ microcapsules on Bifidobacterium. Figure 3 shows the viable count and survival of free Bifidobacterium, Bifidobacterium encapsulated by $\mathrm{BA}$ beads and those by $\mathrm{CA} / \mathrm{BaSO}_{4}$ microcapsules after being immersed in $\mathrm{pH} 2.5$ gastric acid for 1 and $2 \mathrm{~h}$. After $1 \mathrm{~h}$ of immersion, the viable counts of naked Bifidobacterium and Bifidobacterium encapsulated in BA beads were $26.6 \times 10^{6}$ and $33.6 \times 10^{6} \mathrm{CFU} / \mathrm{mL}$, respectively, whereas the viable counts of naked Bifidobacterium and Bifidobacterium encapsulated in $\mathrm{CA} / \mathrm{BaSO}_{4}$ microcapsules exhibited higher value of $40.9 \times 10^{6}$ and $32.6 \times 10^{6} \mathrm{CFU} / \mathrm{mL}$, respectively. Then, the viable count of each group slightly decreased after $2 \mathrm{~h}$, but the tendency did not change. The survival of naked, BA beads and $\mathrm{CA} / \mathrm{BaSO}_{4}$ microcapsule-loaded Bifidobacterium was 36.1\%, 45.6\% and $55.7 \%$, respectively, after $1 \mathrm{~h}$ of immersion. The same tendency appeared after $2 \mathrm{~h}$ of immersion, and the survivals rates were $19.8 \%, 34.2 \%$ and $44.3 \%$, respectively. The results indicated that Bifidobacterium were very sensitive to gastric acid, and BA beads offered certain protective effect. However, compared with BA beads, $\mathrm{CA} / \mathrm{BaSO}_{4}$ microcapsules exhibited the best performance for protecting Bifidobacterium against undesirable gastric acid. For BA beads, the gastric acid can easily diffuse into the core of the beads and kill Bifidobacterium, resulting in low rate of the survival of Bifidobacterium. However, because of the charge repulsion of polycation chitosan located on the surface of microcapsules, it is hard for gastric acid to diffuse into the microcapsules and the survival of Bifidobacterium is much higher.

\section{The release of Bifidobacterium in $\mathrm{CA} / \mathrm{BaSO}_{4}$ microcapsules in simulated intestinal fluid}

The release of Bifidobacterium from $\mathrm{CA} / \mathrm{BaSO}_{4}$ microcapsules was investigated by the dissolution of microcapsules under simulated gastric acid and simulate intestine conditions. As depicted in Figure 4, the release rate of Bifidobacterium from $\mathrm{BA}$ beads and $\mathrm{CA} / \mathrm{BaSO}_{4}$ microcapsules was measured after immersion in $\mathrm{pH} 2.5$ gastric acid for $2 \mathrm{~h}$ and then in intestinal fluid. In pH 2.5 simulated gastric acid, no Bifidobacterium were detected in both bead and microcapsule groups, which demonstrated the favorable stability of beads and microcapsules under acidic environment. However, the release of Bifidobacterium in beads and microcapsules increased following the increase of $\mathrm{pH}$. In $\mathrm{pH} 6.0$ simulated jejunum fluid, only small amount of Bifidobacterium released from BA beads and $\mathrm{CA} / \mathrm{BaSO}_{4}$ microcapsules. When shifted into pH 7.0 simulated ileum fluid, Bifidobacterium were rapidly released from $\mathrm{BA}$ beads and $\mathrm{CA} / \mathrm{BaSO}_{4}$ microcapsules. The release rates of Bifidobacterium in BA beads and $\mathrm{CA} / \mathrm{BaSO}_{4}$
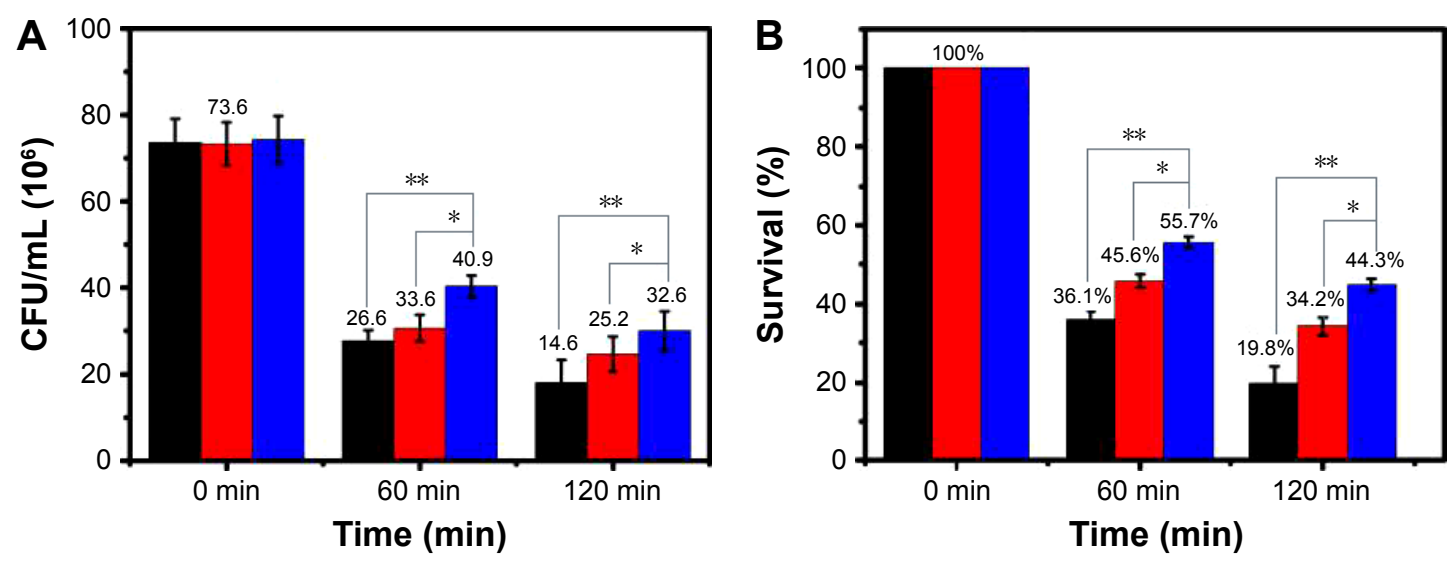

Free Bifidobacterium Bifidobacterium in BA beads Bifidobacterium in $\mathrm{CA} / \mathrm{BaSO}_{4}$ microcapsules

Figure 3 (A) Viable count and (B) survival of free Bifidobacterium, Bifidobacterium in $\mathrm{BA}$ beads and Bifidobacterium in $\mathrm{CA} \mathrm{BaSO}_{4}$ microcapsules after being immersed in $\mathrm{pH} 2.5$ gastric acid. $* \mathrm{P}<0.05, * * \mathrm{P}<0.0 \mathrm{I}$.

Abbreviations: $\mathrm{BA}$, barium-mediated alginate; $\mathrm{CA} / \mathrm{BaSO}_{4}$, chitosan-coated alginate microcapsule loaded with in situ synthesized barium sulfate. 


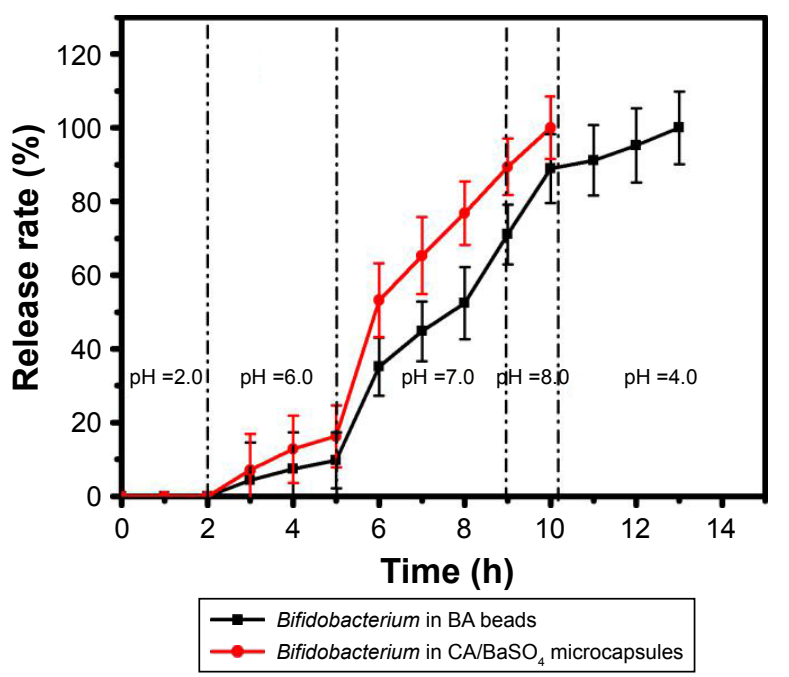

Figure 4 Release rate of Bifidobacterium from $\mathrm{BA}$ beads and $\mathrm{CA} / \mathrm{BaSO}_{4}$ microcapsules after being immersed in simulated solution $\mathrm{pH}$ ranging from 2 to 10 .

Abbreviations: $\mathrm{BA}$, barium-mediated alginate; $\mathrm{CA} / \mathrm{BaSO}_{4}$, chitosan-coated alginate microcapsule loaded with in situ synthesized barium sulfate.

microcapsules were $70 \%$ and $90 \%$, respectively, before entering into simulated cecum fluid. When immersed into simulated cecum fluid, Bifidobacterium in $\mathrm{CA} / \mathrm{BaSO}_{4}$ microcapsules were released completely, but only $90 \%$ of Bifidobacterium in BA beads were released. After BA beads were immersed in simulated small intestine fluid for $3 \mathrm{~h}$, Bifidobacterium released complete from BA beads. It was worth noting that the release rate in microcapsules was much higher than that in beads; it took only about $8 \mathrm{~h}$ for $\mathrm{CA} / \mathrm{BaSO}_{4}$ microcapsules to release all of the encapsulated Bifidobacterium, but about $12 \mathrm{~h}$ for the BA beads. The results demonstrated that $\mathrm{CA} / \mathrm{BaSO}_{4}$ microcapsules exhibited much more satisfactory intestinal-targeted delivery characteristics than BA beads.

\section{$\mathrm{CA} / \mathrm{BaSO}_{4}$ microcapsule-mediated Bifidobacterium delivery for DSS-induced colitis in vivo}

To validate the advantage of $\mathrm{CA} / \mathrm{BaSO}_{4}$ microcapsules in oral administration, DSS-induced mice colitis model was chosen as the animal model. DSS-induced colitis showed significant appearance of diarrhea/loose feces and visible fecal blood, resulting in significant DAI elevation. When the animal model was established, these mice were administrated $2.4 \times 10^{9} \mathrm{CFU}$ naked Bifidobacterium, various amounts of Bifidobacterium encapsulated by $\mathrm{CA} / \mathrm{BaSO}_{4}$ microcapsules of $0.6 \times 10^{9}, 1.2 \times 10^{9}, 2.4 \times 10^{9} \mathrm{CFU}$ and sulfasalazine (clinical drug as positive control). Compared with DSS treated group, the body weight could be dramatically improved after treating with $2.4 \times 10^{9} \mathrm{CFU}$ Bifidobacterium, microcapsules containing
$0.6 \times 10^{9}, 1.2 \times 10^{9}$ and $2.4 \times 10^{9} \mathrm{CFU}$ Bifidobacterium, as shown in Figure 5A. DSS-colitis mice showed much higher DAI scores compared with the other five groups. The DAI data further verifying $\mathrm{CA} / \mathrm{BaSO}_{4}$ microcapsules containing distinctive amounts of Bifidobacterium exhibited similar therapeutic effect with sulfasalazine administration, as shown in Figure 5B. After 11 days of treatment, all DSS-colitis mice showed a significant reduction in their colon length compared with the control groups $(7.6 \pm 0.4 \mathrm{~cm})$. A total of $0.6 \times 10^{9}$ Bifidobacterium encapsulated by $\mathrm{CA} / \mathrm{BaSO}_{4}$ microcapsules group had the shortest length $(5.1 \pm 0.3 \mathrm{~cm})$, followed by $1.2 \times 10^{9}$ Bifidobacterium encapsulated by $\mathrm{CA} / \mathrm{BaSO}_{4}$ microcapsules $(5.8 \pm 0.2 \mathrm{~cm}), 2.4 \times 10^{9}$ Bifidobacterium encapsulated by $\mathrm{CA} / \mathrm{BaSO}_{4}$ microcapsules $(6.5 \pm 0.3 \mathrm{~cm})$, free $2.4 \times 10^{9}$ Bifidobacterium $(5.5 \pm 0.2 \mathrm{~cm})$ or sulfasalazine $(6.4 \pm 0.4 \mathrm{~cm})$ group, as shown in Figure 5C. Interestingly, the colon length was gradually restored with the increasing amount of Bifidobacterium when treatment with $\mathrm{CA} / \mathrm{BaSO}_{4}$ microcapsules encapsulated $2.4 \times 10^{9} \mathrm{CFU}$ Bifidobacterium the colon length was recovered to $85.5 \%$ compared to the normal group. Compared with $\mathrm{CA} / \mathrm{BaSO}_{4}$ microcapsules encapsulated with $2.4 \times 10^{9}$ CFU Bifidobacterium, only $72.4 \%$ of the colon length was recovered after treating with free $2.4 \times 10^{9}$ CFU Bifidobacterium, as shown in Figure 5D. These results further verified that gastric acid could influence the activity of Bifidobacterium. To some extent, $\mathrm{CA} / \mathrm{BaSO}_{4}$ microcapsules can protect Bifidobacterium in gastric acid.

In order to further verify the therapeutic outcome, histological evaluation was carried out to observe the change of anatomical structure of colon wall, as shown in the Figure 6. The normal and $\mathrm{CA} / \mathrm{BaSO}_{4}$ microcapsules group mice had no marked microscopic lesions on histological evaluation of tissues. Compared with normal tissue, DSS treatment induced distortion of crypts, loss of goblet cells (see regions marked by yellow arrows), infiltration of mononuclear cells, submucosal lymphoid hyperplasia, extension around intestinal glands (see regions marked by blue circle) and severe mucosal damage in the colon specimens of colitis (see regions marked by green arrows). However, these pathological changes were gradually alleviated after $\mathrm{CA} / \mathrm{BaSO}_{4}$ microcapsules were mediated by Bifidobacterium treatment in a dose-dependent manner. Decreased inflammatory signs were also observed in colonic tissues harvested from DSS-treated mice with Bifidobacterium. Interestingly, with the increasing concentration of Bifidobacterium, the therapeutic effect was improved. The protective effects against colitis were almost the same between mice treated with microcapsules containing $2.4 \times 10^{9} \mathrm{CFU}$ Bifidobacterium and those treated with sulfasalazine. It has suggested that the secretory immune system of the 

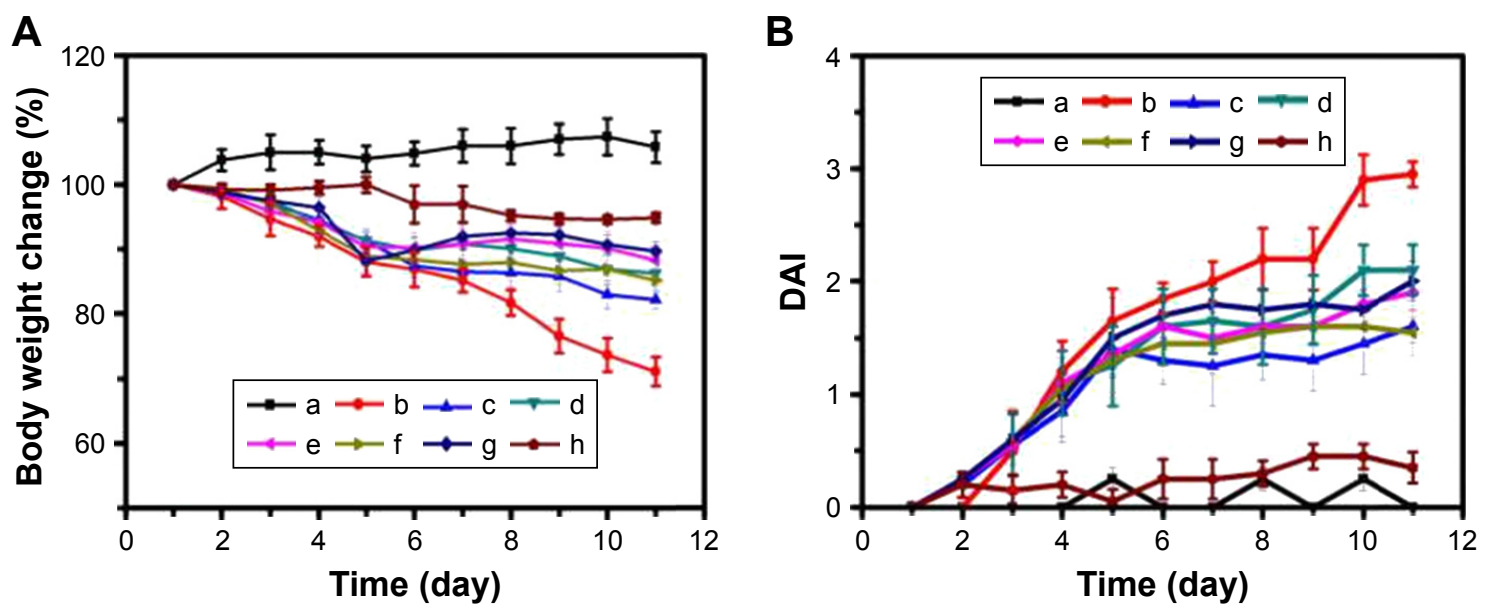

C

D
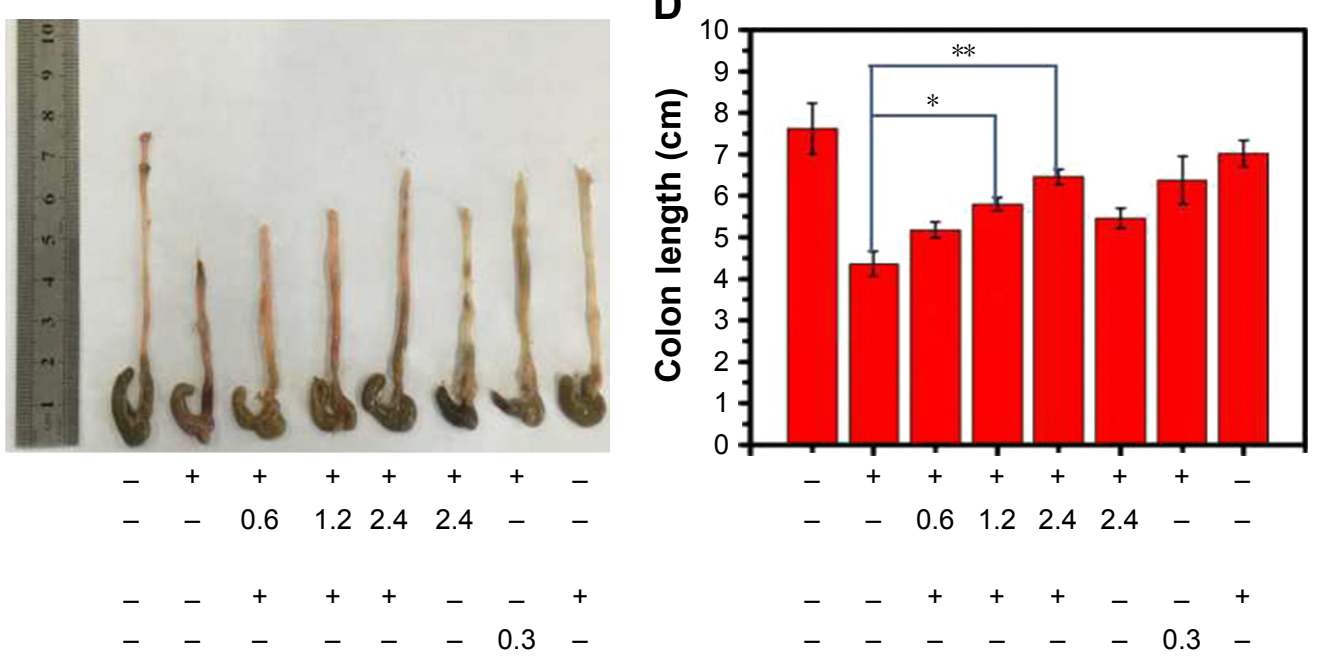

\section{Bifidobacterium}

(CFU) $\times 10^{9}$

\section{Microcapsule}

Sulfasalazine

$(\mathrm{g} / \mathrm{kg} \cdot \mathrm{d})$

$$
\begin{array}{ccccccccc}
- & - & 0.6 & 1.2 & 2.4 & 2.4 & - & - \\
- & - & + & + & + & - & - & + \\
- & - & - & - & - & - & 0.3 & -
\end{array}
$$

Figure $5 \mathrm{CA} / \mathrm{BaSO}_{4}$ microcapsule-mediated Bifidobacterium delivery for DSS-induced colitis treatment in mice. (A) Loss of basal body weight under different treatments during the disease process. a, normal; b, DSS; c, CA/BaSO microcapsule-encapsulated $0.6 \times 10^{9} \mathrm{CFU}$ Bifidobacterium; $\mathrm{d}, \mathrm{CA} / \mathrm{BaSO}_{4}$ microcapsule-encapsulated I.2 $\times 10^{9} \mathrm{CFU}$ Bifidobacterium, e. $\mathrm{CA} / \mathrm{BaSO}_{4}$ microcapsule-encapsulated $2.4 \times 10^{9} \mathrm{CFU}$ Bifidobacterium; f, free $2.4 \times 10^{9} \mathrm{CFU}$ Bifidobacterium; g, sulfasalazine; h, free $\mathrm{CA} / \mathrm{BaSO}_{4}$ microcapsules. (B) DAl under different treatments. (C) The macroscopic appearances and length of colons (D) from each group of mice under different treatments ( $\mathrm{n}=6 \mathrm{per}$ group). Data are presented as mean \pm standard error of the mean. $* P<0.05$, $* * P<0.01$ vs DSS-treated alone group at the same day.

Abbreviations: $\mathrm{CA} / \mathrm{BaSO}_{4}$, chitosan-coated alginate microcapsule loaded with in situ synthesized barium sulfate; DSS, dextran sulfate sodium; DAl, disease activity index.
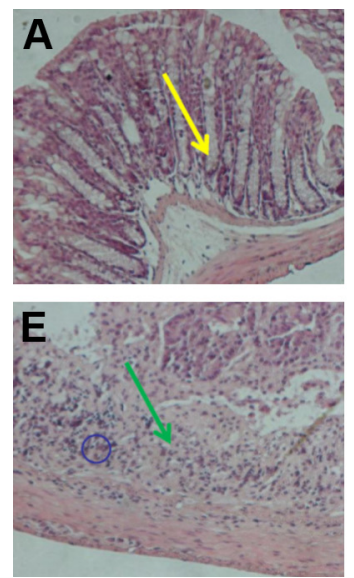
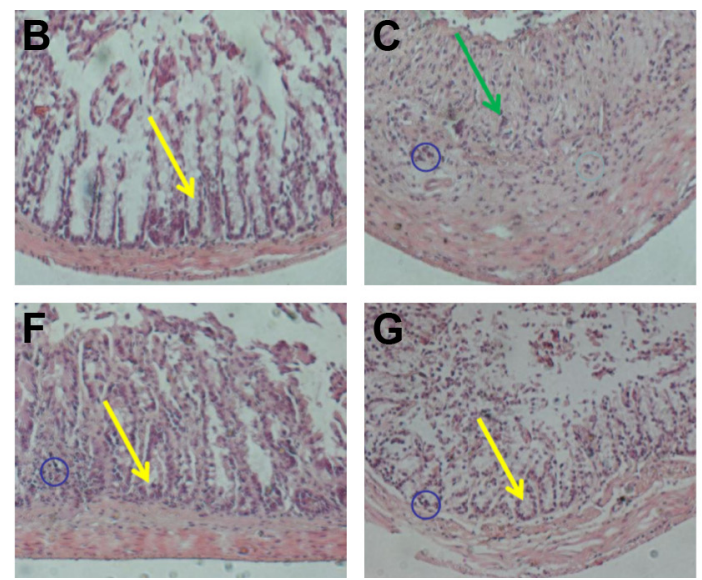
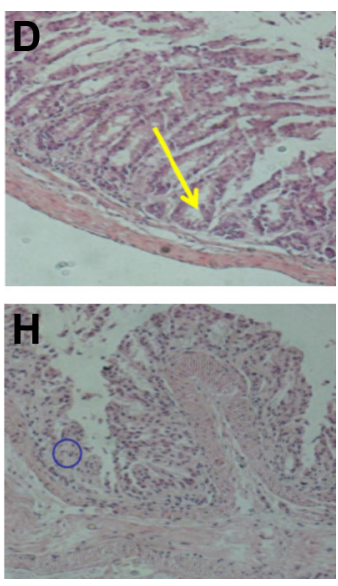

Figure 6 Pathological analysis of colon tissues after distinct treatments using $\mathrm{H} \& \mathrm{E}$ staining assay, magnification $=100 \times$. (A) Normal control, (B) CA/BaSO ${ }_{4}$ microcapsule treatment, (C) DSS induction, (D) sulfasalazine treatment after DSS induction, (E) $0.6 \times 10^{9}$ Bifidobacterium-loading $\mathrm{CA} / \mathrm{BaSO}_{4}$ microcapsule treatment after DSS induction, (F) $1.2 \times 10^{9}$ Bifidobacterium by microcapsule treatment after DSS induction, (G) $2.4 \times 10^{9}$ Bifidobacterium by microcapsule treatment after DSS induction, (H) $2.4 \times 10^{9}$ Bifidobacterium treatment after DSS induction. The blue circles denote infiltration of mononuclear, submucosal lymphoid hyperplasia, and extension around intestinal glands; yellow arrows denote the distortion of crypts and loss of goblet cells; the green arrows denote the severe mucosal damage in the colon.

Abbreviations: $\mathrm{CA} / \mathrm{BaSO}_{4}$, chitosan-coated alginate microcapsule loaded with in situ synthesized barium sulfate; DSS, dextran sulfate sodium. 
gut might be stimulated most effectively by Bifidobacterium, which could actively colonize the mucosal surface of the intestinal tract and release adequate protective antigens. ${ }^{34-36}$ In an inflammatory response, the accumulation of cells within the tissues consisted mainly of neutrophils and monocytes. T-lymphocyte suppressors, which were also involved, played a critical role in the infectious process. It has also been shown that the induction of inflammation and the development of clinical impairment could be prevented by immunosuppression resulting from the appearance of $\mathrm{T}$ cells, predominantly of the $\mathrm{CD} 8^{+}$T-lymphocyte suppressor subset. ${ }^{6}$

\section{Real-time tracking of $\mathrm{CA} / \mathrm{BaSO}_{4}$ microcapsules using $C T$ imaging in vivo}

Capability of $\mathrm{CA} / \mathrm{BaSO}_{4}$ microcapsules in vivo was also evaluated after oral administration by CT imaging. In Figure 7, $3 \mathrm{D}$ renderings of $\mathrm{CT}$ images of the GI tract showed the real-time translocation of $\mathrm{CA} / \mathrm{BaSO}_{4}$ microcapsules through the GI tract in which CT scanned images were obtained at designated time intervals. The main organs of the upper digestive system including stomach, duodenum and a few loops of the small intestine started appearing bright at $2 \mathrm{~min}$ after incorporation of oral $\mathrm{CA} / \mathrm{BaSO}_{4}$ microcapsules, and the CT value of the stomach increased remarkably (denoted as white regions marked by red arrow). After $30 \mathrm{~min}$ of administration, the small intestinal was lighted up due to the presence of much more $\mathrm{CA} / \mathrm{BaSO}_{4}$ microcapsules (denoted as white regions marked by yellow arrow). After $1 \mathrm{~h}$ and $2 \mathrm{~h}$ of administration, the CT signal of small intestine showed an obvious increase, revealing the excellent imaging of the $\mathrm{CA} / \mathrm{BaSO}_{4}$ microcapsules. More importantly, arrangement and sequence of small intestinal loops could be described clearly. After $3 \mathrm{~h}$ of administration, vast majority of CA/ $\mathrm{BaSO}_{4}$ microcapsules was significantly emptied from the small intestine, and the large intestine began to be filled with $\mathrm{CA} / \mathrm{BaSO}_{4}$ microcapsules (see white regions marked by yellow and blue). $\mathrm{CA} / \mathrm{BaSO}_{4}$ microcapsules remained visible after $24 \mathrm{~h}$, which indicated that $\mathrm{CA} / \mathrm{BaSO}_{4}$ microcapsules were located in the sigmoid colon and rectus, and almost all $\mathrm{CA} / \mathrm{BaSO}_{4}$ microcapsules were excreted from body after 2 days, ensuring the neglectable side effect. This observation further demonstrates that the good visibility of $\mathrm{CA} / \mathrm{BaSO}_{4}$ microcapsules under $\mathrm{X}$-ray is beneficial not only for observing the Bifidobacterium migration in the digestive tract but also for evaluating the engraftment of Bifidobacterium in the intestine. ${ }^{40-42}$

\section{Fecal microbiota composition analysis}

In order to systematically assess the performance of CA/ $\mathrm{BaSO}_{4}$ microcapsules in delivering Bifidobacterium for oral administration, fecal microbiota compositions were analyzed using pyrosequencing analysis. As shown in Figure 8,
0 min

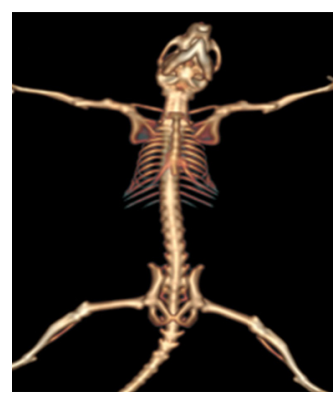

$2 \mathrm{~h}$

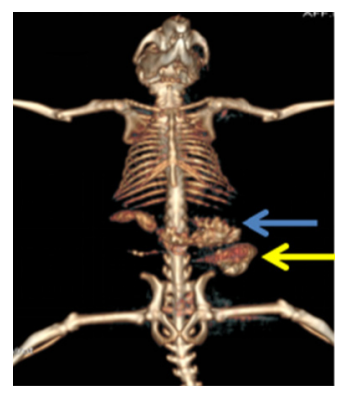

$3 \mathrm{~min}$

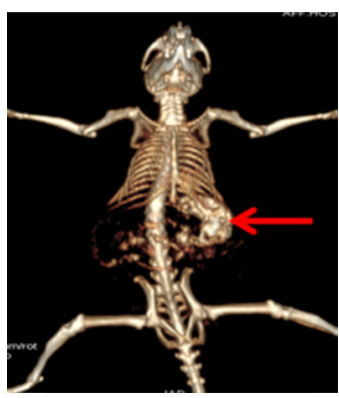

$3 \mathbf{h}$

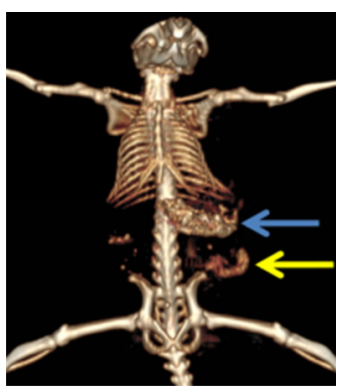

$30 \mathrm{~min}$

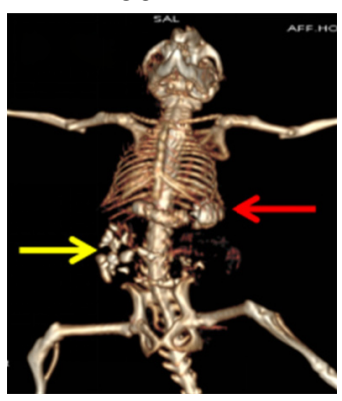

1 day

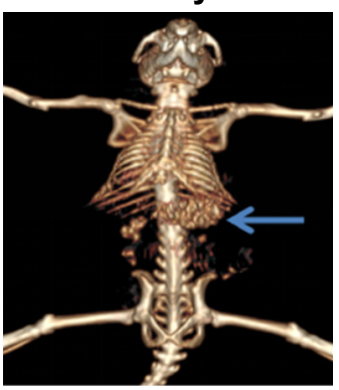

$1 \mathrm{~h}$

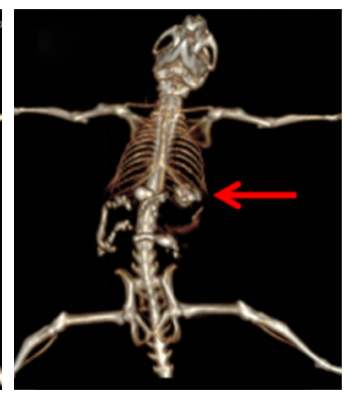

2 days

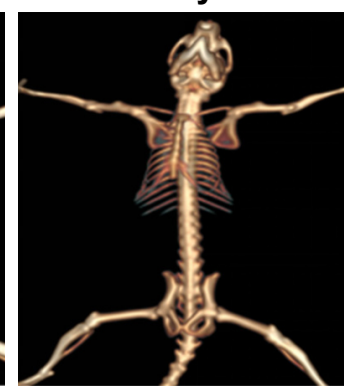

Figure 7 CT scan images of mice at designated time intervals after oral $\mathrm{CA} / \mathrm{BaSO}_{4}$ microcapsules. Red, yellow and blue arrows, respectively, denote stomach, small intestine and large intestine.

Abbreviations: $\mathrm{CT}$, computed tomography; $\mathrm{CA} / \mathrm{BaSO}_{4}$, chitosan-coated alginate microcapsule loaded with in situ synthesized barium sulfate. 


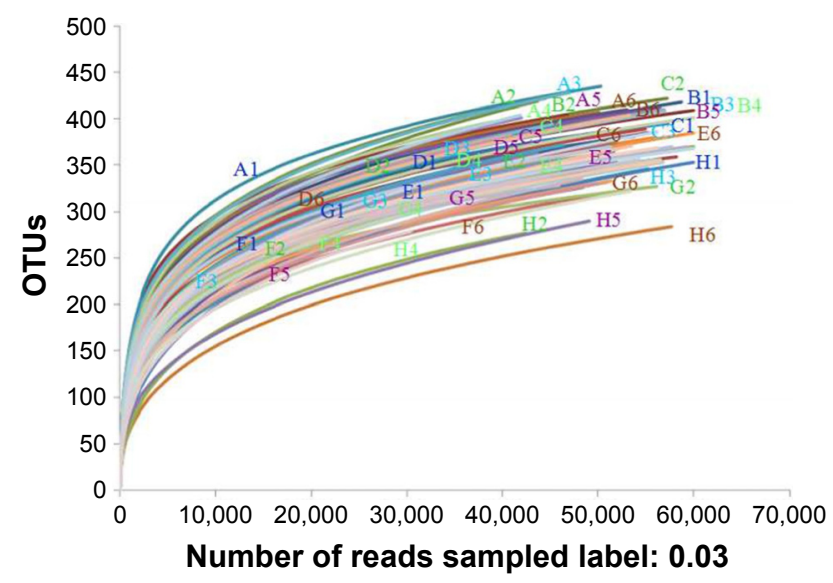

Figure 8 Rarefaction analysis of different samples. Rarefaction curves of OTUs clustered at $3 \%$ phylotype similarity level.

Abbreviation: OTU, operational taxonomic unit.

we found a high microbial diversity in the mice feces and detected 48 species, but the diversity of mice intestinal microbiota with different treating patterns was different. Using parametric test for comparisons, we could find differences in richness and biodiversity among normal group, DSS group, sulfasalazine group, $2.4 \times 10^{9} \mathrm{CFU}$ Bifidobacterium group, microcapsules containing $0.6 \times 10^{9}, 1.2 \times 10^{9}$ and $2.4 \times 10^{9} \mathrm{CFU}$ Bifidobacterium groups at the OTUs cutoff of 0.03 . All of rarefaction curves tended to approach the saturation plateau. Samples from different groups were plotted in the upper part. This rarefaction curve indicated a large variation in the total number of OTUs in different samples, but the sequence coverage was still sufficient to capture the diversity of the bacterial communities. The same tendency was found in species accumulation curves and Shannon-Wiener curves; it tended to approach the saturation plateau, which meant that the database of 16S rRNA gene sequences was very abundant to reflect the vast major of microbial information. ${ }^{43}$

The relative distributions of OTUs in the fecal from each group as a family and genus taxonomical level were explored, as shown in Figure 9. The results show that fecal microbial composition of all mice mostly comprised Bacteroidetes and Firmicutes. Other less abundant phyla were Proteobacteria, Actinobacteria and Tenericutes. Control mice had greater abundances of Bacteroidetes and lower abundances of Firmicutes than DSS-induced mice, which reflected the dominance of OTUs as genus Allobaculum. After being administrated with $\mathrm{CA} / \mathrm{BaSO}_{4}$ microcapsules with various Bifidobacterium, the mice have greater abundances of Bacteroidetes and lower abundances of Firmicutes compared to DSS group mice. With increasing Bifidobacterium, the level of Bacteroidetes was elevated and Firmicutes were declined in all mice, indicating gradual recovering to normal level. ${ }^{34} \mathrm{We}$ performed a nearest shrunken centered classification analysis to investigate which OTUs accounted for differences in composition of the gut microbial community. ${ }^{44}$ In addition, this analysis assesses how well a mouse microbiota is assigned to its treatment group based on its composition.

Detected OTUs were distributed among 28 different bacterial genera. Allobaculum was the most abundant in the cecal contents from each mouse as genus taxonomical level.

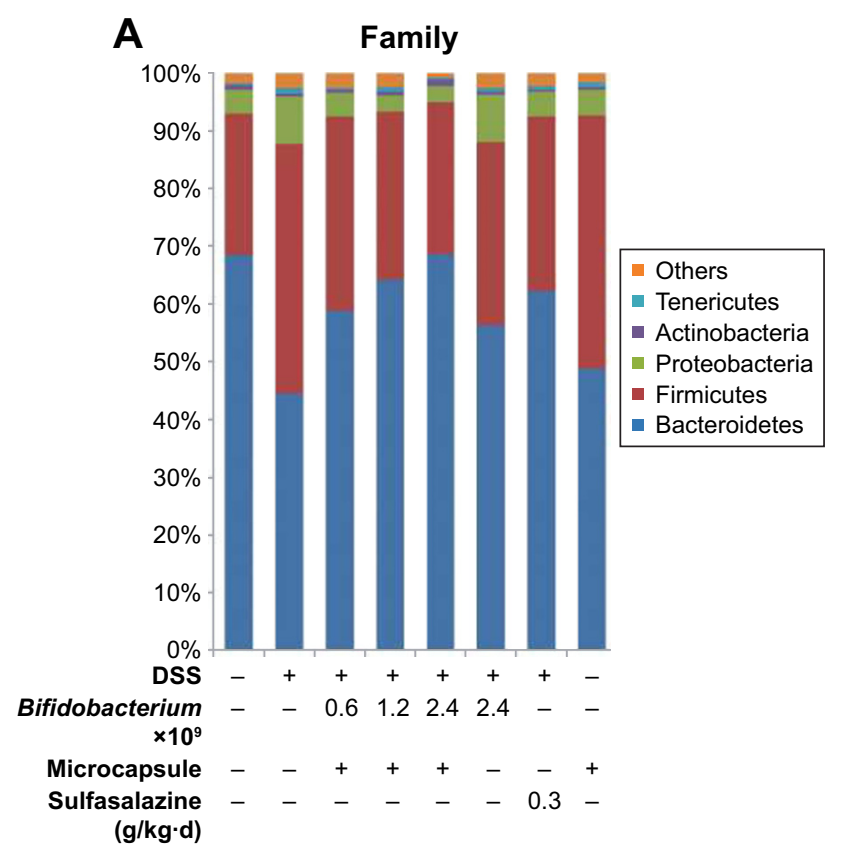

B

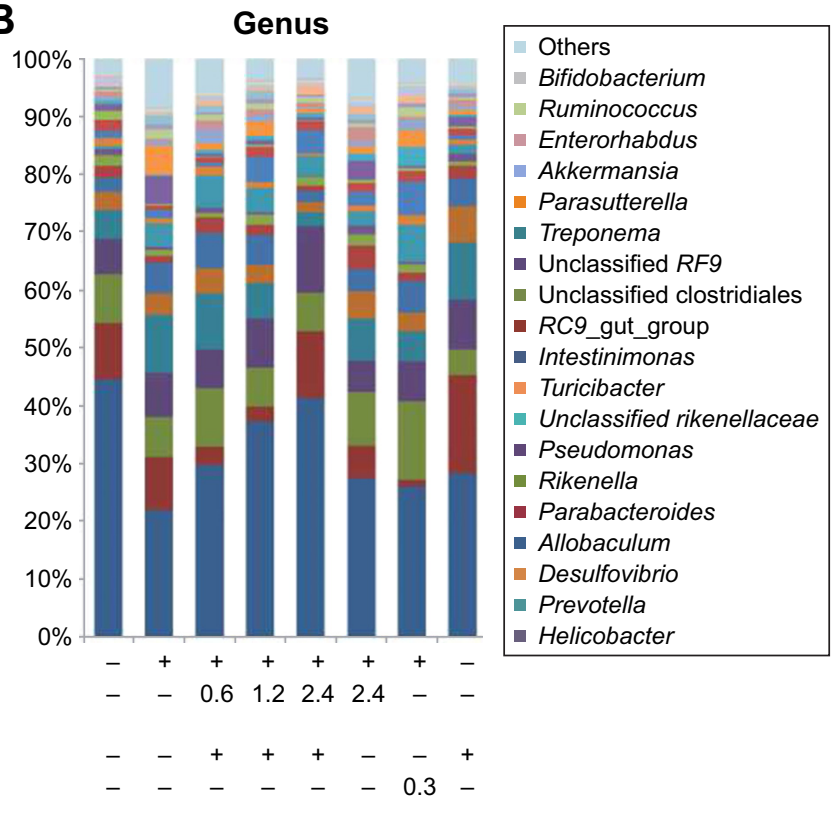

Figure 9 (A) Overall fecal microbiota compositions of each sample with a family level and (B) overall fecal microbiota compositions of each sample with genus level. Abbreviation: DSS, dextran sulfate sodium. 
Unclassified Rikenellaceae was the most abundant in DSS group, which was 2-fold more than normal group. With increasing Bifidobacterium, the level of unclassified Rikenellaceae genus was decreased and Allobaculum genus was increased in all mice. Interestingly, at the genus level, Allobaculum was the most aboundant division in eight groups. Parabacteroides, Rikenella, Pseudomonas, unclassified Rikenellaceae, Turicibacter and Intestinimonas were detected in the group treated by $\mathrm{CA} / \mathrm{BaSO}_{4}$ microcapsules with $2.4 \times 10^{9}$ Bifidobacterium was nearly in the same place compared with the normal group. Bifidobacterium has been widely used and may prevent pathogens from proliferating in the intestinal tract and in the culture environment.

\section{Conclusion}

In this study, we have successfully developed a chitosancoated alginate microcapsule in situ loading the barium sulfate nanoclusters for oral Bifidobacterium delivery and real-time x-ray CT imaging. This synthesized $\mathrm{CA} / \mathrm{BaSO}_{4}$ microcapsule exhibited uniform size distribution and huge hollow core-shell structure, which were beneficial for probiotic loading. During the preparation process, barium ions played dual roles in formation of alginate gelation and barium sulfate nanoclusters. After citric acid-mediated liquidation, the stable transparent shell was formed by electrostatic interaction between chitosan and alginate. The in vitro experiments demonstrated that $\mathrm{CA} / \mathrm{BaSO}_{4}$ microcapsules possessed strong capability to protect the Bifidobacterium from simulated gastric acid attacking and keep them in a good condition under this low $\mathrm{pH}$ environment. This protection may be ascribed to the electrostatic repulsion among the positively charged chitosan molecules, which prevented the gastric acid diffusing across the composite shell. However, the CA/ $\mathrm{BaSO}_{4}$ microcapsule could rapidly release Bifidobacterium in neutral intestinal fluid. In addition, the in situ synthesized $\mathrm{BaSO}_{4}$ nanoclusters endowed the microcapsule with ultrahigh efficiency in absorbing x-ray. The in vivo experiment further confirmed that the radiopaque $\mathrm{CA} / \mathrm{BaSO}_{4}$ microcapsules not only provided a novel platform for efficient protection but also afforded satisfactory intestinal-targeted and non-invasive real-time monitoring character to guarantee the rapid release of Bifidobacterium in the intestine. Finally, using high-throughput sequencing technologies analysis, Bifidobacterium as a group of living microorganism supplements not only altered intestine microbiota composition in bacterial family and genus levels but also alleviated the DSS-induced colitis in mice.

\section{Acknowledgments}

This research was supported by the National Natural Science Foundation of China (No 81301316, 31200676), China Postdoctoral Science Foundation (2013M540425, 2014T70487, 2015M571705), Health and family planning commission of Jiangsu province scientific research subject (H201557), Natural Science Foundation of Jiangsu Province (BK20161317), Zhenjiang key research and development program-social development (SH2016027).

\section{Disclosure}

The authors report no conflicts of interest in this work.

\section{References}

1. Kim BJ, Park T, Moon HC, et al. Cytoprotective alginate/polydopamine core/shell microcapsules in microbial encapsulation. Angew Chem Int Ed Engl. 2014;53(52):14443-14446.

2. Mei L, He F, Zhou RQ, et al. Novel intestinal-targeted Ca-alginate-based carrier for $\mathrm{pH}$-responsive protection and release of lactic acid bacteria. ACS Appl Mater Interfaces. 2014;6(8):5962-5970.

3. D'Orazio G, Di Gennaro P, Boccarusso M, et al. Microencapsulation of new probiotic formulations for gastrointestinal delivery in vitro study to assess viability and biological properties. Appl Microbiol Biotechnol. 2015;99(22):9779-9789.

4. Rosen MJ, Dhawan A, Saeed SA. Inflammatory bowel disease in children and adolescents. JAMA Pediatr. 2015;169(11):1053-1060.

5. Bhakta JN, Ohnishi K, Munekage Y, Iwasaki K, Wei MQ. Characterization of lactic acid bacteria-based probiotics as potential heavy metal sorbents. J Appl Microbiol. 2012;112(6):1193-1206.

6. Perdigón G, Alvarez S, Pesce de Ruiz Holgado A. Immunoadjuvant activity of oral Lactobacillus casei: influence of dose on the secretory immune response and protective capacity in intestinal infections. J Dairy Res. 1991;58(4):485-496.

7. Sanders ME, Akkermans LM, Haller D, et al. Safety assessment of probiotics for human use. Gut Microbes. 2010;1(3):164-185.

8. O'Callaghan A, van Sinderen D. Bifidobacteria and their role as members of the human gut microbiota. Front Microbiol. 2016;7:925.

9. Shah N, Jelen P. Survival of lactic acid bacteria and their lactases under acidic conditions. J Food Sci. 1990;55(2):506-509.

10. Kailasapathy K. Microencapsulation of probiotic bacteria: technology and potential applications. Curr Issues Intest Microbiol. 2002;3(2): $39-48$.

11. Burgain J, Gaiani C, Linder M, Scher J. Encapsulation of probiotic living cells: from laboratory scale to industrial applications. J Food Eng. 2011;104(4):467-483.

12. Cook MT, Tzortzis G, Charalampopoulos D, Khutoryanskiy VV. Microencapsulation of probiotics for gastrointestinal delivery. J Control Release. 2012;162(1):56-67.

13. Corona-Hernandez RI, Álvarez-Parrilla E, Lizardi-Mendoza J, IslasRubio AR, Rosa LA, Wall-Medrano A, et al. Structural stability and viability of microencapsulated probiotic bacteria: a review. Compr Rev Food Sci Food Saf. 2013;12(6):614-628.

14. Ouwehand AC, Salminen SJ. The health effects of cultured milk products with viable and non-viable bacteria. Int Dairy J. 1998;8(9):749-758.

15. Shi LE, Li ZH, Zhang ZL, et al. Encapsulation of Lactobacillus bulgaricus in carrageenan-locust bean gum coated milk microspheres with double layer structure. LWT-Food Sci Technol. 2013;54(1):147-151.

16. Pedroso DL, Thomazini M, Heinemann RJB, Favaro-Trindade CS. Protection of Bifidobacterium lactis and Lactobacillus acidophilus by microencapsulation using spray-chilling. Int Dairy J. 2012;26(2): $127-132$. 
17. Gebara C, Chaves KS, Ribeiro MCE, Souza FN, Grosso CRF, Gigante ML. Viability of Lactobacillus acidophilus La5 in pectin-whey protein microparticles during exposure to simulated gastrointestinal conditions. Food Res Int. 2013;51(2):872-878.

18. Chaikham P, Apichartsrangkoon A, Worametrachanon S, Supraditareporn W, Chokiatirote E, Van der Wiele T. Activities of free and encapsulated Lactobacillus acidophilus LA5 or Lactobacillus casei 01 in processed longan juices on exposure to simulated gastrointestinal tract. J Sci Food Agric. 2013;93(9):2229-2238.

19. Sultana K, Godward G, Reynolds N, Arumugaswamy R, Peiris P, Kailasapathy K. Encapsulation of probiotic bacteria with alginate-starch and evaluation of survival in simulated gastrointestinal conditions and in yoghurt. Int J Food Microbiol. 2000;62(1-2):47-55.

20. Adhikari K, Mustapha A, Grün IU, Fernando L. Viability of microencapsulated bifidobacteria in set yogurt during refrigerated storage. J Dairy Sci. 2000;83(9):1946-1951.

21. Yeung TW, Üçok EF, Tiani KA, McClements DJ, Sela DA. Microencapsulation in alginate and chitosan microgels to enhance viability of Bifidobacterium longum for oral delivery. Front Microbiol. 2016; 7:494.

22. Martin MJ, Lara-Villoslada F, Ruiz MA, Morales ME. Effect of unmodified starch on viability of alginate-encapsulated Lactobacillus fermentum CECT5716. Lwt-Food Sci Technol. 2013;53(2):480-486.

23. Shi LE, Li ZH, Li DT, et al. Encapsulation of probiotic Lactobacillus bulgaricus in Alginate-milk microspheres and evaluation of the survival in simulated gastrointestinal conditions. J Food Eng. 2013;117(1): 99-104.

24. Esmaeilzadeh J, Nazemiyeh H, Maghsoodi M, Lotfipour F. Evaluation of the effect of Psyllium on the viability of Lactobacillus acidophilus in alginate-polyl lysine beads. Adv Pharm Bull. 2016;6(3):337-343.

25. Lee KY, Heo TR. Survival of Bifidobacterium longum immobilized in calcium alginate beads in simulated gastric juices and bile salt solution. Appl Environ Microbiol. 2000;66(2):869-873.

26. Younes I, Rinaudo M. Chitin and chitosan preparation from marine sources. Structure, properties and applications. Mar Drugs. 2015;13(3): 1133-1174.

27. Andersen T, Bleher S, Eide Flaten G, Tho I, Mattsson S, Škalko-Basnet N. Chitosan in mucoadhesive drug delivery: focus on local vaginal therapy. Mar Drugs. 2015;13(1):222-236.

28. Piyasi M, Kishor S, Shweta S, Kundu PP. Formulation of $\mathrm{pH}$-responsive carboxymethyl chitosan and alginate beads for the oral delivery of insulin. App Polymer Sci. 2013;129(2):835-845.

29. Gombotz WR, Wee SF. Protein release from alginate matrices. $A d v$ Drug Delivery Rev. 2012;64:194-205.

30. Malmo C, La Storia A, Mauriello G. Microencapsulation of Lactobacillus reuteri DSM 17938 cells coated in alginate beads with chitosan by spray drying to use as a probiotic cell in a chocolate soufflé. Food Bioprocess Technol. 2013;6(3):795-805.
31. Lee DW, Lim C, Israelachvili JN, Hwang DS. Strong adhesion and cohesion of chitosan in aqueous solutions. Langmuir. 2013;29(46): 14222-14229.

32. Barnett BP, Arepally A, Stuber M, Arifin DR, Kraitchman DL, Bulte JW. Synthesis of magnetic resonance-, X-ray- and ultrasound-visible alginate microcapsules for immunoisolation and noninvasive imaging of cellular therapeutics. Nat Protoc. 2011;6(8):1142-1151.

33. Wang Q, Qian K, Liu S, et al. X-ray visible and uniform alginate microspheres loaded with in situ synthesized $\mathrm{BaSO}_{4}$ nanoparticles for in vivo transcatheter arterial embolization. Biomacromolecules. 2015; 16(4):1240-1246.

34. Zhou FX, Chen L, Liu XW, et al. Lactobacillus crispatus M206119 exacerbates murine DSS colitis by interfering with inflammatory responses. World J Gastroenterol. 2012;18(19):2344-2356.

35. Liu W, Guo W, Wu J, et al. A novel benzo[d]imidazole derivate prevents the development of dextran sulfate sodium-induced murine experimental colitis via inhibition of NLRP3 inflammasome. Biochem Pharmacol. 2013;85(10):1504-1512.

36. Bermúdez-Humarán LG, Motta JP, Aubry C, et al. Serine protease inhibitors protect better than IL-10 and TGF- $\beta$ anti-inflammatory cytokines against mouse colitis when delivered by recombinant lactococci. Microb Cell Fact. 2015;14:26.

37. Ravussin Y, Koren O, Spor A, et al. Responses of gut microbiota to diet composition and weight loss in lean and obese mice. Obesity (Silver Spring). 2012;20(4):738-747.

38. Poncelet D, Neufeld RJ. Shear breakage of nylon membrane microcapsules in a turbine reactor. Biotechnol Bioeng. 1989;33(1):95-103.

39. Ghaffarian R, Herrero EP, Oh H, Raghavan SR, Muro S. Chitosanalginate microcapsules provide gastric protection and intestinal release of ICAM-1-targeting nanocarriers, enabling GI targeting in vivo. Adv Funct Mater. 2016;26(20):3382-3393.

40. Wei B, Zhang X, Zhang C, et al. Facile synthesis of uniform-sized bismuth nanoparticles for CT visualization of gastrointestinal tract in vivo. ASC Appl Mater Interfaces. 2016;8(20):12720-12726.

41. Zhang M, Ju H, Zhang L, et al. Engineering iodine-doped carbon dots as dual-modal probes for fluorescence and X-ray CT imaging. Int $J$ Nanomedicine. 2015;10:6943-6953.

42. Du F, Lou J, Jiang R, et al. Hyaluronic acid-functionalized bismuth oxide nanoparticles for computed tomography imaging-guided radiotherapy of tumor. Int J Nanomedicine. 2017;12:5973-5992.

43. Fan W, Tang Y, Qu Y, Cao F, Huo G. Infant formula supplemented with low protein and high carbohydrate alters the intestinal microbiota in neonatal SD rats. BMC Microbiol. 2014;14:279.

44. Knights D, Kuczynski J, Koren O, et al. Supervised classification of microbiota mitigates mislabeling errors. ISME J. 2011;5(4):570-573.
International Journal of Nanomedicine

\section{Publish your work in this journal}

The International Journal of Nanomedicine is an international, peerreviewed journal focusing on the application of nanotechnology in diagnostics, therapeutics, and drug delivery systems throughout the biomedical field. This journal is indexed on PubMed Central, MedLine, CAS, SciSearch $®$, Current Contents $® /$ Clinical Medicine,

\section{Dovepress}

Journal Citation Reports/Science Edition, EMBase, Scopus and the Elsevier Bibliographic databases. The manuscript management system is completely online and includes a very quick and fair peer-review system, which is all easy to use. Visit http://www.dovepress.com/ testimonials.php to read real quotes from published authors. 